\title{
PRODUÇÃO DE SUPLEMENTO DE FIBRAS A PARTIR DE TRATAMENTO ENZIMÁTICO EM RESÍDUO DE FRUTAS E HORTALIÇAS
}

\author{
Matheus Ajackson Barros Lima ${ }^{1}$; Fernanda do Carmo da Silva ${ }^{2}$; Mariana Pulmar Seljan ${ }^{1}$; \\ Roberta Melquiades Silva de Andrade ${ }^{1,4}$; Édira Castello Branco de Andrade Gonçalves ${ }^{1,2}$ \\ (ediracba.analisedealimentos@unirio.br)
}

1. Escola de Nutrição - Universidade Federal do Estado do Rio de Janeiro (UNIRIO)

2. Instituto de Biociências - Universidade Federal do Estado do Rio de Janeiro (UNIRIO)

3. Programa de Pós-graduação em Alimentos e Nutrição (PPGAN) - Universidade Federal do Estado do Rio de Janeiro (UNIRIO)

4. Universidade Federal do Rio de Janeiro (UFRJ)-Campus UFRJ Macaé

Grandes quantidades de resíduos sólidos são produzidas anualmente pela indústria de processamento de alimentos, e estes estão ganhando atenção por representarem uma nova e econômica fonte de ingredientes funcionais, como fibras alimentares. De acordo com a Comissão Codex Alimentarius (CODEX, 2009), fibra alimentar pode ser definida como polímeros de carboidratos com dez ou mais unidades monoméricas que não são hidrolisados por enzimas endógenas no intestino delgado dos humanos. Dessa forma, o presente estudo teve por objetivo aplicar tratamento enzimático em resíduo de frutas e hortaliças (FFH) visando o aumento do teor de fibras, para obtenção de suplemento vegetal. O resíduo de frutas e hortaliças utilizado como matéria prima foi obtido a partir da produção de uma bebida funcional e contém cerca de $48 \%$ de fibras totais. Para o tratamento enzimático, foi utilizada a enzima Viscozyme e um delineamento composto central associado a metodologia de superfície de resposta foi proposto para avaliar a influência dos parâmetros de concentração da enzima (15- $45 \mathrm{FBG})$ e temperatura $\left(30^{\circ} \mathrm{C}-60^{\circ} \mathrm{C}\right)$ sobre o teor de fibras totais. Os experimentos foram realizados durante 30 minutos cada e após o tratamento enzimático, as amostras foram filtradas em filtros de poliéster e a parte sólida retida no filtro colocada em placas de Petri e seca em estufa $\left(60^{\circ} \mathrm{C}\right)$, sendo esta a fração utilizada para as análises do teor de fibras totais, através do método enzimático-gravimétrico. Foi possível observar que todas as condições experimentais promoveram aumento significativo do teor de fibras. O ponto ótimo de rendimento (aproximadamente $72 \%$ de fibra total) foi observado aplicando temperatura na faixa entre 45 a $60^{\circ} \mathrm{C}$ e concentração de enzima intermediário (entre 15 a 35 FBG). Uma ingestão adequada de fibras na dieta (aproximadamente 30g/dia) parece estar associado a benefícios funcionais à saúde humana. Entretanto, sabe-se que o consumo de fibras pela população decaiu nos últimos anos e a indústria de alimentos tem buscado desenvolver produtos enriquecidos ou suplementos de baixo custo para auxiliar na adequação do consumo diário de fibras. Neste sentido, o tratamento enzimático utilizado no presente estudo é considerado uma tecnologia simples e de baixo custo por tratar-se de um processamento sustentável, uma vez que a matéria prima utilizada é um resíduo da indústria alimentícia. Além disso, através deste tratamento, verifica-se a possibilidade de obter maior concentração de fibra alimentar a partir de um mix de resíduos vegetais, o que evidencia vantagens tecnológicas e nutricionais.

Palavras-chave: Tratamento enzimático; Resíduo; Fibras totais 